\title{
Snoring: analysis, measurement, clinical implications and applications
}

\author{
F. Dalmasso, R. Prota
}

Snoring: analysis, measurement, clinical implications and applications. F. Dalmasso, R. Prota. (C) ERS Journals Ltd. 1996.

ABSTRACT: Snoring was described in literature even before medicine. Common definitions do not consider acoustic measurements of snoring. In this paper we discuss the main pathophysiological aspects of snoring and the snoring-sleep relationship as the generating mechanisms.

Snoring can be analysed and measured by the following methods: 1) LeqEquivalent Continuous Sound Level, which only quantifies noisiness, annoyance, and damage to the partner's and snorer's hearing; 2) Power Spectrum, with frequency values, formantic structure data and typical shape, which can help to distinguish simple snoring from heavy snoring with obstructive sleep apnoea syndrome (OSAS); 3) Linear Prediction Code (LPC) method, which can define the crosssectional area (CSA) of the upper airways and which locates sites of obstruction.

Simulated snoring analysis with LPC and with simultaneous fluoroscopy permits the definition of CSA and the identification of three snoring patterns: nasal, oral and oronasal. Snoring is an important sign of sleep-related breathing disorders (SRBD), of the upper airway resistance syndrome (UARS), and of the OSAS. Snoring is a symptom of nasal obstruction and is associated with cardiovascular diseases and nocturnal asthma as a trigger or causative factor; however, its acoustic features in these disorders are not well-defined. Home monitoring of snoring is very useful for epidemiology and is mandatory, together with heart rate and arterial oxygen saturation $\left(\mathrm{Sa}_{\mathrm{a}, \mathrm{O}_{2}}\right)$, to screen $\mathrm{SRBD}$.

Eur Respir J., 1996, 9, 146-159.
Pulmonary Division and Laboratory of Respiratory Physiopathology, Mauriziano "Umberto I" Hospital, Turin, Italy.

Correspondence: F. Dalmasso Divisione di Pneumologia

Lab. di Fisiopatologia Respiratoria

Ospedale Mauriziano "Umberto I"

Largo Turati 62

10138 Torino

Italy

Keywords: Acoustics of snoring simulated snoring

snoring

snoring-asthma

snoring monitoring

Received: May 181995

Accepted for publication June 191995
In literature, even before medicine, Charles Dickens (1812-1870), with remarkable insight, closely observed and vividly described sleep, its disorders and its facets. Considering that he had no medical experience and lived in an age when sleep was not formally studied, the descriptions that are now recognizable in medicine were depicted with great accuracy. In particular, in The Pickwick Papers (Chapters 4, 11, 28 and 54), he described a form of hypersomnia with loud snoring, gluttony and obesity in a teenager called Joe, a big fat boy who was the valet of Mister Wardle. Others of his characters showed the snoring and forms of sleep apnoea syndrome, as in "Barnaby Rudge" (Chapter 33) or in "The Uncommercial Traveller" (Chapter 13). For a long time, snoring attracted only the attention of writers (Shakespeare, Flaubert, Balzac, Maupassant, Mauriac, Celine etc.), and in the past it was considered a normal phenomenon, a curiosity or, at most, a noise disturbing the sleeping partner or room mate.

Only between the years 1960 and 1980, with the clear identification of sleep apnoea syndrome (SAS) and its classification [1-3], was the significance of snoring evaluated as the most important sign of the obstructive sleep apnoea syndrome (OSAS). The first surgical approach to the treatment of snoring and sleep apnoea was proposed by IKEMATSU [4] in 1960, and reproposed in 1981 by Fujita et al. [5]. In the same year, Sullivan et al. [6] described a ventilatory system with nasal continuous positive airway pressure (NCPAP), which is useful in eliminating snoring and sleep apnoea. Habitual snoring is a quite common sign in up to $60 \%$ of the adult male population $[7,8]$. It can begin as an isolated phenomenon, and can then meet with disturbances and disorders of various importance, up to OSAS.

\section{Definition}

Snoring is a respiratory sound (or noise) which originates during sleep, and so can be nocturnal or diurnal. It is a typical inspiratory sound, even though a small expiratory component can be heard or recorded (especially in OSAS patients) with different spectral features. We must distinguish it from all the other sounds (noises) which can be heard, recorded and analysed during sleep (sleep sounds syndrome, (SSS)) [9, 10].

The definition of snoring should also be related to the type of measure employed for sound and noise signals. 
Table 1. - Heavy snorers disease

\begin{tabular}{ll}
\hline Stage 0 (preclinical) & $\begin{array}{l}\text { Heavy snoring alone } \\
\text { Intermittent snoring and } \\
\text { daytime somnolence }\end{array}$ \\
Stage I (incipient) & $\begin{array}{l}\text { Intermittent snoring and } \\
\text { profound daytime somnolence }\end{array}$ \\
Stage III (complicated) & $\begin{array}{l}\text { Intermittent snoring, profound } \\
\text { daytime somnolence and } \\
\text { cardiorespiratory complications }\end{array}$ \\
\hline
\end{tabular}

(Adapted from LUGARESI and co-workers [9]).

Generally, the pathological importance of snoring has been related to its intensity $(\mathrm{dB})$, maximal and mean snoring intensity (dBmax and dBmean, respectively), timing (continuous or interrupted), and the length of time during sleep (snoring index: numbers of snores per hour of sleep; snoring frequency: numbers of snores per minute of snoring time). Acoustically, snoring is due to vibration of the walls of the oropharynx when the patency of the upper airway is altered by some of the numerous factors which regulate it. LUGARESI et al. [11], monitoring snoring during polysomnographic studies, have classified various stages of the so-called "heavy snorers disease", and have distinguished the "continuous" snoring pattern from the "intermittent" snoring pattern (table 1). Snoring is the earliest and most consistent sign of upper airway dysfunction leading to sleep apnoea/ hypopnea syndrome. The American Sleep Disorders Association (ASDA) [12] defined snoring as "Loud upper airways breathing, without apnoea or hypoventilation, caused by vibrations of the pharyngeal tissues. It can be classified as mild, moderate and severe on the basis of frequency, body position, and disturbance for other people (spouse, bed partner)". Moreover, ASDA defined primary snoring as snoring without sleep disruption and absence of complaint of insomnia or excessive daytime sleepiness [12].

In accordance with HoFFSTEIN et al. [13], we have previously [10] emphazised the necessity of an accurate definition of snoring in terms of objective measurement, as recent studies of snoring and asthma have also shown [14-16]. These studies raise the question of distinguishing between snoring and other nocturnal sounds, detected on the chest wall. Furthermore, simple monitoring of sound intensity on the sternal notch is not sufficient, and more complex techniques of acoustic analysis need to be employed to properly define and measure snoring.

From the acoustical point of view, snoring has been analysed and measured on the frequency and time domain, and it must be defined with these parameters. Snoring has also been used, with a particular acoustic technique, as a means to evaluate the cross-sectional area (CSA) of the upper airway (UA) [17], as described below in the section "Acoustics of snoring" (table 2).

\section{Anatomical and pathophysiological aspects}

The upper airway (UA) extends from the lips and nostrils to the vocal chords. It can be considered as comprised of numerous cylindrical segments of different CSA and of unequal length; and therefore, from the physical point of view, the UA acts as "tubes" of Venturi [18]. The passage of an airflow through these airways should satisfy the equation of Bernoulli and the law of Poiseuille [18]. The airflow can be laminar or turbulent as a function of the value of the Reynolds number [18]. The UA only partially satisfies these formulae, because of its particular anatomical and functional features; the UA behaviour, in a particular way, is based on different characteristics of its segments, which can be stiff (rigid) or collapsible, and on their compliance, which depends on morphology and trophicity.

In general, it is sufficient to consider three segments: 1) The first (proximal) segment is formed by the nasal cavities and rhinopharynx. It has an osseous-cartilaginous structure, is rigid, and not deformable or collapsible under the effect of the inspiratory pressure (suction pressure activated by inspiratory muscles); 2) The second (medium) segment is the oropharynx, a typical collapsible structure which can decrease its diameter (CSA) with the approach of the walls under sufficient inspiratory negative pressure. The collapsible part of this segment is formed anteriorly by the soft palate, the lymphoidamygdalic apparatus and the hyoid-lingual apparatus; and 3) The third (distal) segment is formed by the larynx, a cartilaginous and rigid structure which is neither deformable nor collapsible under inspiratory pressure.

Table 2. - Techniques and methods employed to measure snoring

\begin{tabular}{|c|c|c|}
\hline Spikes in sound intensity of breathing & $\begin{array}{l}>45 \mathrm{~dB} \\
>60 \mathrm{~dB}\end{array}$ & \\
\hline Maximum snoring intensity & $\mathrm{dB} \max$ & \\
\hline Mean snoring intensity & $\mathrm{dB}$ mean & (Hottstein) \\
\hline Number of snores $\cdot h^{-1}$ of sleep & SI & \\
\hline Number of snores $\cdot \mathrm{min}^{-1}$ of snoring & SF & \\
\hline Leq & $\mathrm{dBa}$ & (Wilson, Dalmasso) \\
\hline Power Spectrum (FFT) & & (Righini, Dalmasso, Spence, Perez-Padilla) \\
\hline Sonogram & & (Righini, Dalmasso, Perez-Padilla) \\
\hline Formants structure (F0.1.2.3) & & (Righini, Dalmasso, Perez-Padilla) \\
\hline LPC method for CSA & & (Righini, Dalmasso, Spence) \\
\hline
\end{tabular}

SI: snoring index; SF: snoring frequency; Leq: A-weighted energy mean of the noise level averaged over the measurement period; FFT: fast Fourier transform; LPC: Linear Prediction Code; CSA: cross-sectional area. 
The UA patency is regulated by the activity of numerous muscles, which act as dilators or constrictors. In particular, the decreasing patency of the oropharynx segment depends on the activity of three groups of muscles. The pharyngeal duct, which extends posteriorly from the nasal cavities and mouth to the larynx and oesophagus, has a muscular wall. There are five pharyngeal muscles, three of which are constrictors and two elevators. During contraction, the constrictors, acting as a sphincter, bring the posterior wall close to the anterior and lateral walls, and so reduce the CSA. The tongue plays an important role with its seventeen muscles, having four pairs of symmetric muscles plus a single median muscle to regulate its movement.

In a very schematic way, three main groups of muscles are involved in the loss of patency of the oropharynx: 1) the muscles of the soft palate; 2) the muscles of the back tongue; and 3) the pharyngeal uvular muscles.

In pathophysiological conditions, the different sites of anatomical or functional narrowing, from nose to larynx, are, therefore, represented in all three segments. The segment which is typically collapsible is the second, i.e. the oropharynx.

The following simultaneous factors are necessary to produce snoring: 1) sleep; 2) flow limitation (see "Sleep effects on the UA"); 3) vibrating structure, which is represented by the soft palate and other soft parts of the oropharynx behaving like a Starling resistor [18]; 4) reduction of CSA of the UA; and 5) thorax bellows, which act with suction inspiratory pressure.

The causes which determine snoring are the same as those which can lead to upper airway resistance syndrome (UARS) and/or OSAS on the basis of their degree of severity. We can consider: 1) general causes (metabolic, in particular obesity which involves almost $100 \%$ of snores; hormonal; and ageing); 2) Local causes (congenital and acquired, correction of which can eliminate the trouble); and 3) non demonstrable causes (a high percentage of which induces oropharyngeal dysfunction).

\section{Sleep effects on the UA: snoring-sleep relationship}

Several factors influence UA resistance. They decrease with the increase of lung volume and breath rate $[19,20]$. They increase with head flexion, mucous congestion [21] and, particularly, during sleep. The most important effect of sleep is the decrease of activity of all of the muscles of the UA and its variability, according to the muscular group and sleep phase. The contraction of dilator muscles of the UA, during inspiration, anticipates the closing trend of the collapsible segment of the UA [22, 23]. During sleep, the decreasing activity of these muscles makes the two segments of UA less stable, and can explain the increasing resistances.

In healthy subjects, during sleep, no direct correlation has been found between the increased resistance of the UA and variation in the activity of the genioglossus and geniohyoideus muscles [24-27]. This fact could demonstrate that the reduction in CSA, which determines the increase in resistance, is not located at the level of the back tongue. Recently, it was reported that the significant decrease in activity of the tensor palatini muscle, during sleep, demonstrated a good correlation with increased resistance [28].

In snoring subjects, there are some anatomical and functional abnormalities, and the intensity and frequency of snoring correlate with these [29]. A flow limitation, constant or decreasing flow independent of the driving pressure, during sleep has been reported by several authors in healthy nonsnorers [30], in healthy snorers [31], and in OSA patients. In these situations, sleep seems to provoke a flow limitation [32], with a decrease in the tone of the muscles of the UA.

LIISTRO et al. [33], in heavy snorer patients without OSAS and in OSAS patients, found that flow limitation precedes the snoring action during sleep, in all cases. They recognize two main patterns of snoring, with cineradiographic technique, which can differ in heavy snorers and in OSA patients.

A study by HofFSTEIN et al. [13] showed that snoring did not influence the sleep "architecture" in general. Evaluating snoring distribution among the various stages of sleep, they found that light snorers snored evenly throughout all stages; on the other hand, heavy snorers tended to snore more in slow-wave and rapid eye movement (REM) sleep than in other sleep stages. The snoring frequency of light snorers was the same in all sleep stages, whereas it was significantly higher in slow-wave sleep in heavy snorers. These data agree with the recent observations of SKATRUD and DEMPSEY [31], who showed that total pulmonary resistance depended on the sleep stage, and that snorers demonstrated an increase in resistance during the deeper stages of sleep.

Perez-PAdilla et al. [34] also found that snoring distribution was irregular throughout the sleep stages; in particular, it occurred only in stage II and in slow-wave sleep of normal young adults. They found, however, that heavy snorers snored longer in stage II, probably because this is the longest sleep stage.

\section{Acoustics of snoring}

\section{Snoring sounds generation}

Snoring sounds originate in the upper airway, which behaves as a collapsible tube tending to collapse predominantly in the inspiratory phase. Therefore, the production of snoring sounds has been compared to the production of wheezes in the bronchial tree, represented by a series of collapsible tubes, which tend to collapse predominantly in the expiratory phase. This inversion of phases of collapsibility of the upper $v s$ central airway is due to the mechanism of inspiration-expiration. From a physical point of view, mathematical and biochemical simulation models have been worked out and employed to explain sound generation [35-37].

Two main models for interpreting snoring sounds can be considered. One model is that of "relaxation oscillations" of a collapsible tube described by BERTRAM [38]. 
The oscillations produce a partial or complete closure of the lumen with maximal constriction which moves upstream along the tube. The partial or total closure of the lumen, opening with a sudden equalization of upstreamdownstream pressure could generate an explosive sound. This model of the mechanism is similar to that which is applied for crackles generation in the peripheral airways. According to PEREz-PADIlla [39], this type of explosive feature of snoring, in frequency and time domain, is more common in the snoring of patients with OSA. The second model [37, 40], based on the "flutter theory", employs a long corrugated channel, changing in CSA, with elastic walls and resistance which interacts with a gas flow. This model fits well with the shape and characteristics of the bronchial and pharyngeal wall. On the basis of this second model, the fluttering walls of the collapsed segment, where there is flow limitation, are the source of snoring. The flutter frequency tends to decrease as the CSA becomes smaller or the thickness increases. The two theoretical models for explaining snoring sound generation meet with the observations of fluoroscopic imaging of vibrating uvula, soft palate and pharyngeal wall $[33,41]$.

\section{Acoustic investigations}

Snoring is an acoustic signal and can be described in terms of quality, and above all quantity, by means of acoustic analysis techniques, which can give information on the mechanism, loudness, intensity, CSA and sites of obstruction of the upper airway. Snoring sounds can be easily and precisely detected by a miniature electret microphone, hung infront of the patient's mouth at a distance of $15-20 \mathrm{~cm}$, and/or by microphones directly applied above the suprasternal notch, or on the neck or chest wall. The signal can be recorded on a hi-fi Stereo cassette or digital audio tape (DAT) recorder, or sent through an analogue-digital converter directly to a computer system for subsequent analysis. The snoring signal can be detected alone or with other parameters, such as in polysomnographic and/or fluoroscopic investigations or in ambulatory, home monitoring devices. Snoring can be also picked up by a condenser microphone placed at $15-20 \mathrm{~cm}$ from the mouth. A noise analyser performs the statistical analysis of the sound level, expressed in $\mathrm{dB}(\mathrm{A})$ (frequency A-weighted curve). Three main methods can be applied to analyse and measure the recorded snoring: 1) Leq-Equivalent Continuous Sound Level; 2) Power Spectrum (PS); and 3) Linear Prediction Code (LPC) for CSA.

Leq-Equivalent Continuous Sound Level. Leq is the Aweighted energy mean of the noise level averaged over the measurement period. It can be considered as the continuous steady noise level which would have the same total A-weighted acoustic energy as the real fluctuating noise measured over the same period of time, and is defined as:

$$
\text { Leq }=10 \log _{10} \frac{1}{t} \int_{0}^{\tau} \quad\left(\frac{P \mathrm{~A}(t)}{P_{\mathrm{o}}}\right)^{2} \mathrm{~d} t
$$

where $t$ is the total measurement time; $P \mathrm{~A}(t)$ is the Aweighted instantaneous acoustic pressure; $P_{0}$ is the reference acoustic pressure $(20 \mathrm{~Pa})$; and $\mathrm{A}$ is an electrical filter "A" of sound level meter internationally standardized [41].

The statistical analysis of the snoring signal during the night by Leq technique reports the data on Leq, L5, L95. The quantities L5 and L95, expressed in $\mathrm{dB}$ (A), are the sounds levels which are exceeded in $5 \%$ and $95 \%$ of the test period and are representative of the highest levels $(5 \%)$ and of background levels (95\%), respectively. The duration of the evaluation takes place in about $8 \mathrm{~h}$ and data are produced every $10 \mathrm{~min}$, so that the evolution time can be well evaluated. The global value of Leq (7 h) is $55.7 \mathrm{~dB}(\mathrm{~A})$. The lower values of L95 indirectly confirm the low level of the background noise in the test room. The complete Leq study has been reported previously [17, 42].

The results of the analysis of snoring in terms of equivalent sound level (Leq) confirm that snoring can be quantified as regards the sound energy emitted during sleep, and can be correlated to the other parameters measured with polysomnography. When a larger number of subjects and patients are studied, this technique will help to differentiate the population of pathologic patients, guide the therapeutic approach, and follow the results of treatment. On the other hand, this technique provides only quantitative and objective data and not further information on the anatomy and pathophysiology of the upper airway. The technique measures noisiness, annoyance, and damage to the partner's hearing. In addition, it allows verification of possible damage to the snorer's hearing. For these reasons, Leq analysis can be useful in forensic medicine to judge cases of requested separation and damage claims.

Power spectrum (PS). A digital, 2-channel frequency analyser is used for this technique (Fast Fourier transformer (FFT)). The transformation of data from time domain to frequency domain is carried out by the FFT algorithm implemented on a PC:

$$
\mathrm{S}(f)=\int_{-\infty}^{\infty} \mathrm{x}(t) \mathrm{e}^{-\mathrm{i} 2 \pi f \mathrm{t}} \cdot \mathrm{d} t
$$

where $f$ is frequency in $\mathrm{Hz}, t$ is time in $\mathrm{s}$, e is exponential function, $\mathrm{i}$ is an imaginary unit.

The analyser works on a data maximal length of 256 $\mathrm{K}$ and, therefore, the sampling frequency of the analogueto-digital (A/D) converter determines the maximal time duration of the sample which can be analysed in real time. The snoring phenomenon, when detected in front of the patient's mouth, can be completely described by using a frequency scale of $10 \mathrm{kHz}$, to which a sampling frequency of 25.6 must correspond. A lower sampling frequency of $2.56 \mathrm{kHz}$ was used only for the recording of "time history" of the signal of more respiratory cycles (100 s) [17].

Figure 1a shows the snoring signal in one snorer over a period of $10 \mathrm{~s}$, where four respiratory cycles are present. Figure 1b shows the "power spectrum" of the 
a)
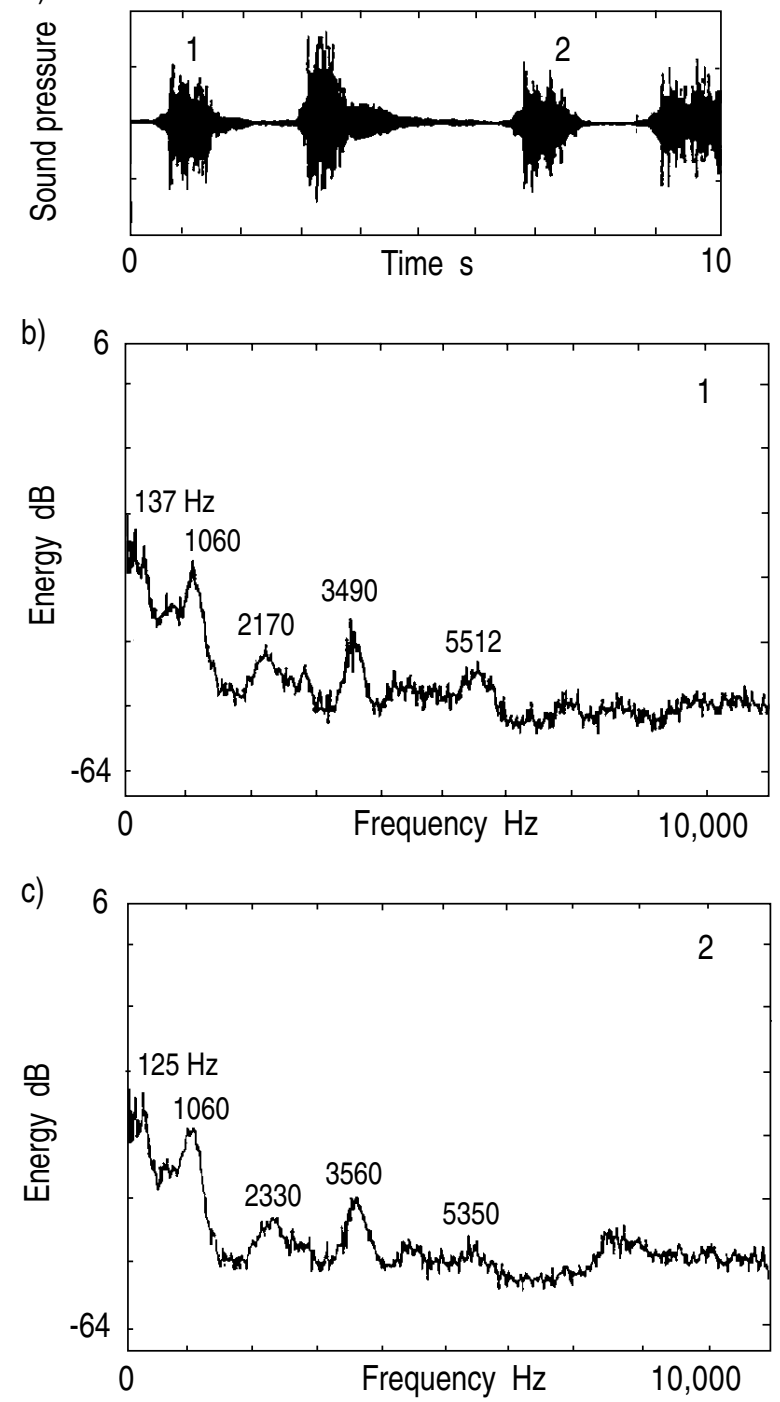

Fig. 1. - a) graphic representation of waveforms of snoring events, b) the averaged spectrum shape of event 1 in fig. 1a is represented with values $(\mathrm{Hz})$ of its "formants". c) the averaged spectrum shape of event 2 in fig. 1a with values of its "formants".

snoring signal corresponding to section 1: Figure 1c shows the "frequency spectrum" of the snoring signal corresponding to section 2 . The greater part of the energy content is below $5,000 \mathrm{~Hz}$ and the main components lie in the low frequency range, at about $130 \mathrm{~Hz}$, and in the mean frequency range, at about 1060, 2200 and 3500 $\mathrm{Hz}$. The graphic representation of the signal in time domain and frequency domain was shown on the display of the analyser and printed on a digital plotter. Since the distribution of energy of the frequency spectrum changes within a single event or during a respiratory cycle, a three-dimensional representation of snoring was performed. This allowed visualization of the time evolution of the spectrum. The analyser elaborated subsequent data segments, each 1,024 points in length (at the same frequency of $25.6 \mathrm{kHz}$, which corresponds to 40 $\mathrm{ms}$ ) overlapping the nearest segment by 512 points. The result was a three-dimensional graph of energy-frequencytime of the sound signal (fig. 2). a)

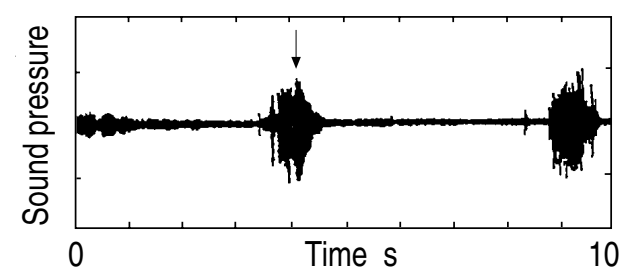

b)

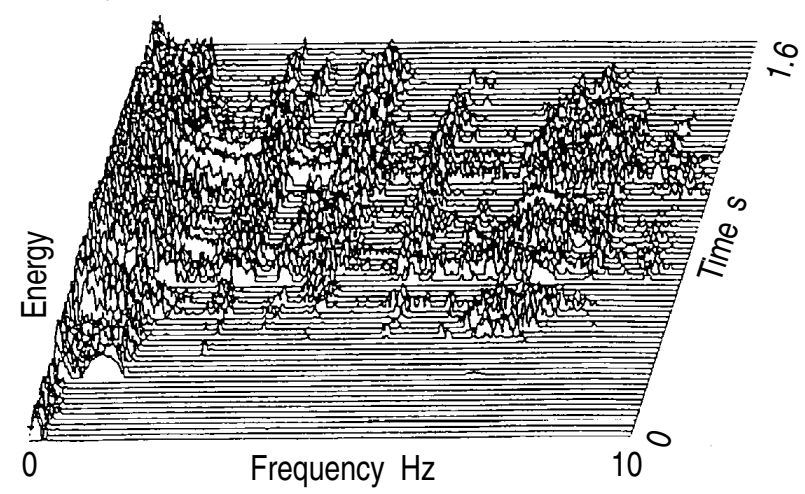

Fig. 2. - a) Time variation of snoring sound pressure; and b) time variation of the frequency spectrum of the event marked in (a).

Examining many cases of simulated and real snoring during sleep, energy was mainly concentrated in the low frequency range at the beginning of snoring, and at middle and high frequencies (up to $7 \mathrm{kHz}$ ) at the end. The structure of the spectrum results being of formantic type, practically identical in every cycle of the sequence examined.

The analysis on the frequency domain characterizes the snoring sound as a nonstationary signal. The spectrum shows a fundamental frequency and a "formants type" structure. In experimental phonetics, the formants are the acoustic analogue of the shape and size of the vocal duct. Each "formant" is characterized by frequency, bandwidth and amplitude level, and its range depends on the shape of the resonant cavities. The different conditions in which the subjects and the patients who snore can affect the formants range in the frequency spectrum. The snoring spectra at the mouth and over the trachea have a similar frequency trend below $1,500 \mathrm{~Hz}$, but the tracheal spectrum lacks the components of mean and high frequencies. This is due to the low-pass filter of the aluminium cup of the system's microphone applied to the sternum. Furthermore, the signal is filtered through the patient's chest wall. Thus, better information is obtained, as necessary for this type of study, when snoring is detected externally to the chest, near the mouth [9, 17]. Meslier et al. [43], monitoring tracheal breath sound in snoring patients with OSAS, found no significant change in frequency spectrum with sleep stages. They found evolution of fundamental frequency during a snore (stability, increase of fundamental frequency, sudden variations of frequency).

Perez-Padilla and Remmers [39] found, in spontaneous snorers, three main patterns of snoring (nasal, oral and oronasal) which present characteristic spectra. They may 
make it possible to recognize the type of respiration. We agree with these data, but in real snoring it is not easy to distinguish the three patterns which can associate with each other for many reasons (rhinitis, pharyngolaryngitis, body position, consumption of alcohol, pills, etc.). We found these three typical patterns (see section on "Simulated snoring") in a very exclusive way and with typical UA shape, defined with LPC, in simulated snoring $[44,45]$.

The same author [46] found the most different spectra in OSAS snorers; in particular, the first post-apnoea snore constituted by white noise with more power at higher frequency. Therefore, he proposed that the ratio of power above $800 \mathrm{~Hz}$ to power below $800 \mathrm{~Hz}$ could distinguish simple snorers from those with OSAS.

SPENCE et al. [47], in patients who underwent standard polysomnography, recorded snoring on the sternal notch and examined snores during Stage II sleep using the FFT technique. They found a significant correlation between median frequency of snore and apnoea-hypopnoea index. This fact may be related to intrathoracic pressure changes or differing sites of UA obstruction. Thus, the spectral analysis values, the "formants type" structure and the shape of spectrum help to distinguish simple snoring from loud snoring with OSAS, even though with a certain overlap of data.

Linear prediction code $(L P C)$ method for CSA. For this type of procedure, we assume that the upper airway is represented by a simplified model made up of segments of rigid tubes, having the same length, and each with different CSA. The first corresponds to the lips and the last to the glottis. The parameters of the model are the CSA, Si $(i=1,2 \ldots n)$, which are evaluated by the snoring sound signal. The presence of obstruction in the upper airway is demonstrated by a smaller area than the one considered normal in this section, $\mathrm{Si}$. The algorithm of evaluation of the CSA is based on the LPC of the signal. This model is of autoregressive (AR) type having a polynominal shape; its coefficients permit the calculation of the signal spectrum and the reflection coefficients of the sound waves, which spread in the duct in correspondence to each cylindrical tube segment $[9,48]$. The data used for the prediction of the snoring sound signals are: 1) sampling time $0.1 \mathrm{~ms}$ (corresponding to $10 \mathrm{kHz}$ ); 2) predictor order; 3) pre-emphasis of $6 \mathrm{~dB} /$ octave. Based on these data, the length of the acoustic tube used for the model is $18.7 \mathrm{~cm}$, which is close to the mean of the upper airway in adults (from lips to larynx). The frequency field extends from 0 to $5,000 \mathrm{~Hz}$, which is enough to characterize the sound spectrum of snoring. This spectrum is characterized by the resonance of the duct.

This model, largely used in speech analysis [49], has been implemented on a PC Olivetti 386 with a mathematical co-processor 387 and data acquisition card (Metrabyte DAS 16) for sound processing. A card (Canon ION-PC) has been used to process images when these ones are performed simultaneously to snoring. This card permits the use of enhancement and extraction techniques of the contours and the zooming of the fluoroscopic images.

The acoustic technique LPC, to determine the CSA, used by our group, is without restriction and much easier to perform, especially during the recording phase. The analysis has been carried out using the LPC, which can be implemented on a microcomputer. As stated previously, it is possible to calculate the coefficients of reflection of an acoustic filter having a nonuniform cylindrical tube shape, which emits the given signal on the basis of the coefficients of the signal linear predictor. Since the system of the upper airway (mouth+oropharynx or nose+rhinopharynx) is assimilated with an acoustic tube, it is natural to wonder how the acoustic filter, estimated using LPC, can be considered as a model of the upper airway system.

As an example, the snoring signal of a chronic obstructive lung disease (COLD) patient with OSA was processed by analysing the on-line signal with LPC technique. The snoring signal was analysed during nocturnal monitoring with the segments of "Time History", which lasts about $2.5 \mathrm{~min}$, with apnoeas lasting more than $15 \mathrm{~s}$ between each snore. Figure $3 \mathrm{a}-\mathrm{d}$, related to the case, shows the radius of the CSA which changes from the lips (left hand side) to the glottis (right hand side), and in the oropharynx region becomes smaller until obstructive apnoea appears [50].

Clinically, our interest is to obtain useful detail by monitoring the sleep of habitual and heavy snorers who may suffer from repeated attacks of obstructive sleep
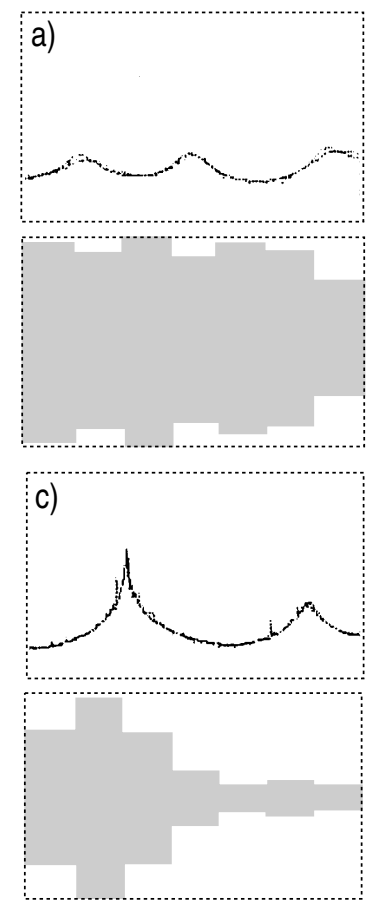

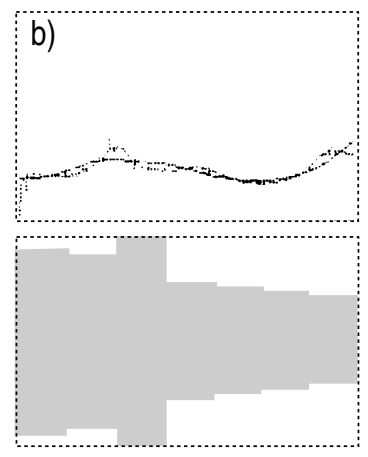

d)

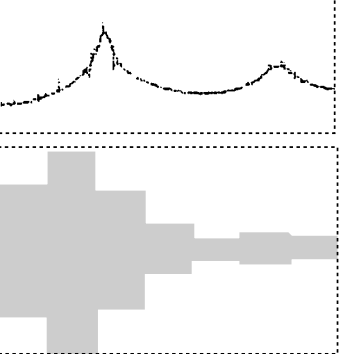

Fig. 3. - Cross-sectional area (CSA) of upper airway (UA) estimated by frequency spectrum with Linear Prediction Code (LPC) technique of a progressive obstruction in a patient with COLD and OSA. In the figures a), b), c), and d) the top section shows the frequency spectrum of the snoring sound and the bottom shows the relative shape and size of the estimated CSA from the lips (left side) to the glottis (right side). The progression of the figures shows the CSA gets smaller up to apnoea. 
apnoea, by means of a noninvasive and easily planned method. Since the theoretical approach to the problem would have been very hard both acoustically and physiologically, based on previous experience of speech analysis, we decided on an experimental approach to snoring based on the analysis of sounds and radiographic images obtained simultaneously. It is with this technique that we can identify the snoring patterns and, in particular, two main patterns, i.e. oral and nasal. These two patterns can be identified and correlated both with the formants type structure and the measured form of the CSA of the upper airway model, and much more easily measured by radiographic images. Examining the "real" (during sleep) snoring by the fluoroscopic-acoustic technique was very hard for many reasons: technical, ethical and organizational. Heavy snorers with sleep apnoea were examined, but no definite correlations between the snoring signal and the fluoroscopic signal can yet be given. Some of these problems may be solved by using the "napping" technique.

Further improvements are necessary. Digital acoustical analysis of snoring has numerous advantages: recording the snoring sound in bed, at home or in hospital (in a room with low background noise) is easy, it is the first step in saving time, and may avoid the use of expensive tests. The recorded signals can be sent to the laboratory or analysed "on-line"; in this way, the results can be obtained in sufficient time to help in determining a therapeutic approach. This method could be adopted for screening; it is considered noninvasive, cheap, and can be easily performed in bed without qualified personnel.

\section{Simulated snoring studies}

The simulation of snoring after sufficient training can make it possible to perform the same investigations more easily than in sleeping subjects or patients, and in particular it makes it possible to perform some types of tests, such as fluoroscopy and cineradiography, which can hardly be performed at the bedside overnight. On the basis of these observations, some authors have investigated the patterns of simulated snoring in healthy subjects with imaging techniques.

LIISTRO et al. [51], during simulated snoring of healthy subjects, observed an increase in supraglottic resistance compared with quiet breathing, but, as expected, they did not find flow limitation preceding the beginning of snoring. Using cineradiography, they observed and demonstrated two different patterns of simulated snoring: through the nose, when the soft palate is in close contact with the back tongue, and the uvula alone presents high-frequency oscillations; and through the mouth, when the whole soft palate oscillates at high frequency. During simulated snoring, PEREz-PADILla and REMMERs [39] and LIISTRO et al. [51] observed an out-of-phase pressure and flow relationship.

DALMASSO and co-workers $[44,50]$ compared the patterns of simulated snoring obtained with fluoroscopic images with those obtained simultaneously through LPC analysis of snoring, and considered the possibility offe- red by the acoustic investigation to identify them. The fluoroscopic data of the upper airway and simulated snoring, simultaneously recorded, provided interesting information concerning snoring and movements of the upper airway. During quiet breathing, the pharyngeal airway showed the maximum calibre, with the soft palate and the uvula equally distant from the tongue base and posterior pharyngeal wall. During simulated snoring in situation (fig. 4a), i.e. free snoring (oronasal), the soft palate rose and vibrated, reducing the anteroposterior diameter of the oropharynx. The snoring sounds spectra showed a formants type structure [9] and the CSA tended to assume a horn-like form, with maximum opening at the lips. In situation (fig. 4b), i.e. through the nose only (nasal), which was difficult and sometimes imperfect, close contact was shown between the soft palate and the back of the tongue. Snoring had its own formants type structure, whereas CSA did not always have a shape like that of the upper airway; it was often like a Helmoltz Resonator with the neck at the nostrils when the manoeuvre was perfect. In situation (fig. 4c), i.e. through the mouth (oral), we observed ample undulations of the whole soft palate and a consistent approach to the posterior wall of the oropharynx, with a reduction of the sagittal diameter. The formants pattern and the CSA were similar to the latter situation, giving more evidence to the horn-like shape. Three typical spectral peaks are recognized, respectively, at 250,370 and $550 \mathrm{~Hz}$. The 2nd formant is due to the nasal cavity and predominates in the (b) situation, but is almost unrecognizable in the spectra of simulated snoring from (c). All the three peaks are remarkable in the spectra of simulated snoring from situation (a) [45].

Figures $4 \mathrm{a}-\mathrm{c}$ show the results of snoring sound and image digital processing according to the three types of simulated snoring (oronasal, nasal and oral) with simultaneous fluoroscopic images of seven voluntary, healthy, nonhabitual snorer subjects. In each example, the sound segment analysed corresponds to the upper airway underlined in the radiographic image, digitally defined, as seen at the bottom of each table. The snoring waveform can also be seen with different time-expanded forms; the frequency spectrum at the top on the right, and below this the CSA of the airway model, calculated with the LPC. The shape of CSA and its relative values are very similar during snoring through the mouth and during free snoring (oronasal route). During snoring through the nose the shape of CSA and its relative values can change, but they always remain remarkably different from the other two (mouth and oronasal routes). During nasal snoring (although not easy to perform) the uvula presents oscillations of small amplitude and relatively high frequency. We found the frequency of oscillations during inspiration in nasal snoring, due to the uvula alone, to be $104.2 \pm 18.9 \mathrm{~Hz}$. During free snoring, and even more so during mouth snoring, the whole soft palate oscillates and these oscillations were found to be quite ample with a lower frequency, $31.5 \pm 7.3 \mathrm{~Hz}[44,45]$.

Although fluoroscopy enables dynamic observation of the movements of UA during the snoring phenomenon; it does not permit a direct measure of CSA, giv- 
a)

Time
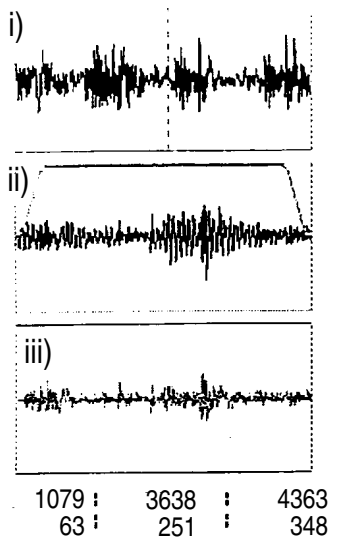

Frequency
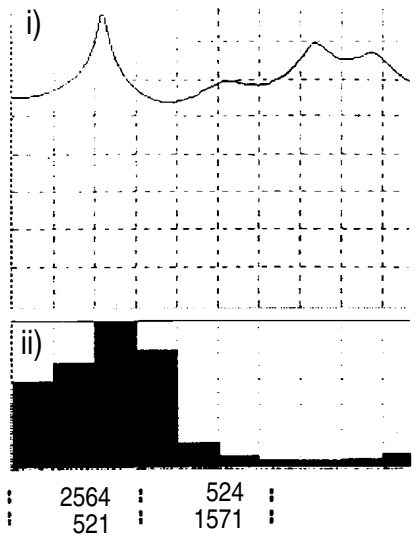

b)

Time

1) why

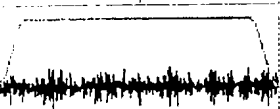

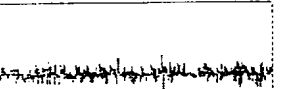

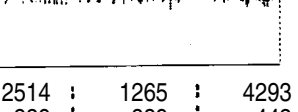

Frequency

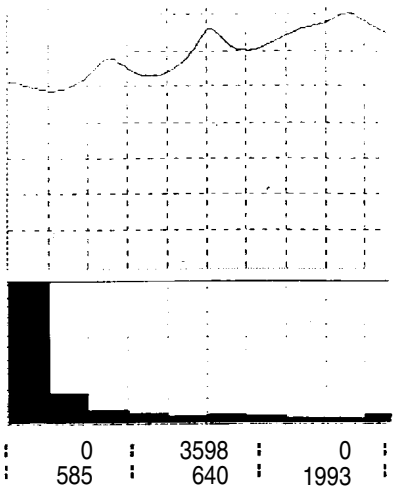

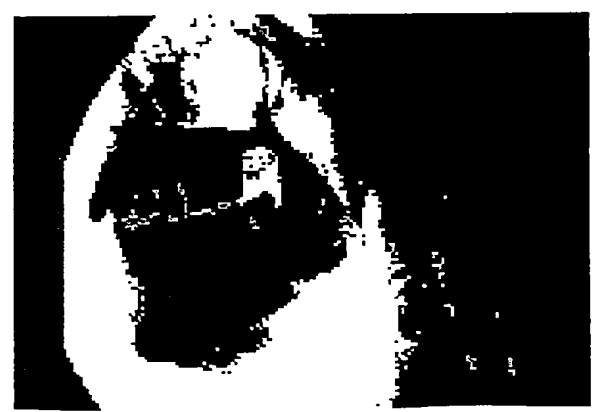

c)
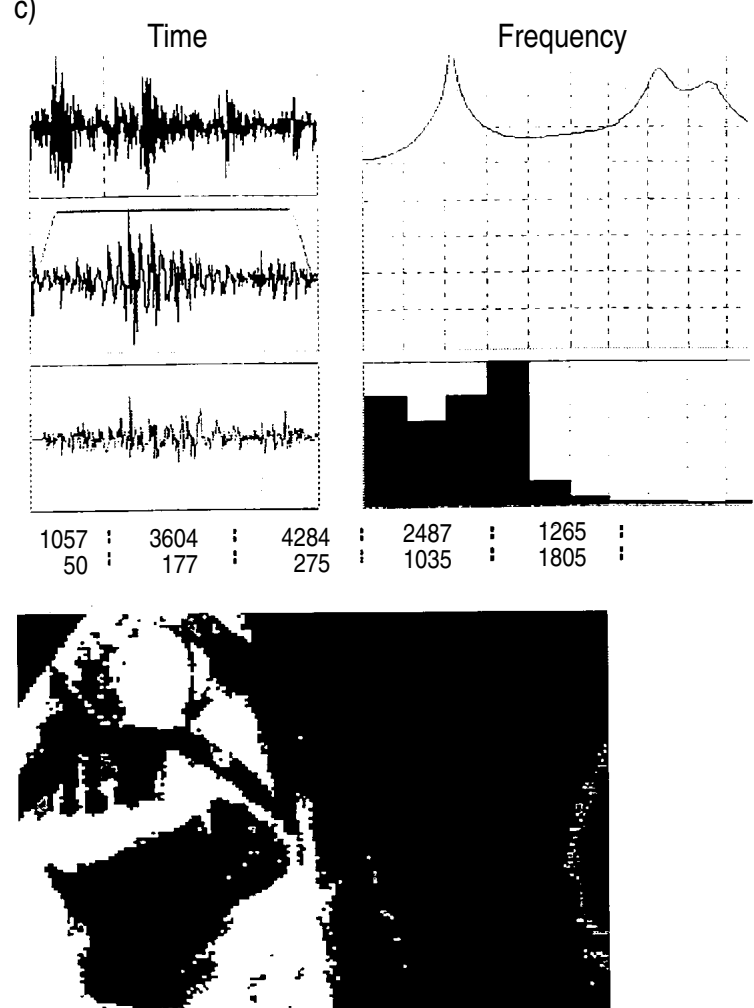

Fig. 4. - Comparisons of cross-sectional area (CSA) estimated by means of sound and image processing. The figures $\mathrm{a}$, $\mathrm{b}$ and $\mathrm{c}$ relate, respectively, to oronasal, nasal and oral snoring. In each, the upper left panel shows: i) the signal waveform of the snoring with the mark of the section analysed; ii) the expanded waveform of the section; and iii) its derivate. The upper right panel shows: i) the power spectrum; and ii) the CSA estimated by Linear Prediction Code (LPC) signal processing. The lower panel shows radiographic image of the upper airway (UA) corresponding to the mark on the signal waveform. The number lines in the middle refer to the formant frequencies and to the corresponding bandwidth below. 
ing only a sagittal imaging [44]. Such a problem is found in the study of speech. Recently PERRIER et al. [52], performed scans of the vocal duct with computerized tomography. In this way, deriving the sections of area and sagittal diameters, the authors found it possible to convert the sagittal dimensions in area functions. They employed an empirical formula of this type:

$$
\mathrm{A}=\mathrm{C} \times \mathrm{D}^{1.5}
$$

where $\mathrm{A}$ is the CSA, D the sagittal diameter, and $\mathrm{C}$ a coefficient obtained, section by section, on statistical basis in order to reduce the mistake of an approximation of the model. Fluoroscopy still remains an excellent method to evaluate the dynamics of snoring. The possibility of quantitatively determining CSA beginning with sagittal measurements, amplifies the field of action of fluoroscopy and further experimental confirmation should be sought in this direction.

Evaluation of CSA of the UA based on analysis of the acoustic signal with LPC, provides confirmatory data with those provided by radioscopic investigation, especially in as far as the shape of the oral route and the narrowing site are concerned. A good correlation between CSA, determined by fluoroscopy, and CSA defined by means of snoring analysis with the LPC method in simulated snoring [44], permits the validation of this technique and its application (as already performed by us) to "real" snoring. The limitation of snoring itself as an infallible diagnostic sign for apnoea is obvious. Some acoustic characteristics, which are now much better defined than in the past (e.g. dynamics of the UA), and some "formantics" features [44], useful to define the entity and site of narrowing, make the monitoring of screening, based at present on recording and arbitrary quantification alone, more incisive.

\section{Snoring clinical implications and applications}

\section{Snoring as a sign of abnormality}

In each patient's history, the presence or absence of snoring should always be considered, in particular if he complains of some disturbances. Obviously, this is not easy to obtain from the patient himself. If snoring is present, the history and related diagnostic tests help to determine whether: 1) the patient is just a snorer without other disorders (nonhabitual, habitual, simple snorer); 2) the patient presents not only snoring but also sleep disorders or breathing disturbances during sleep; 3) the patient or the partner report apnoeas during sleep and other daytime disturbances. When snoring is admitted, the patient's history must be recorded accurately and, consequently, some investigations must be made; a specialized doctor may be required.

The history should indicate the functional nocturnal and daily disturbances, and as far as possible the onset of them. Falling asleep suddenly can arouse suspicion. The reported characteristics of snoring are important, i.e. habitual or not, recent or longstanding, continuous or intermittent, in dorsal supine position or in other positions. Also the type of sleeping, i.e. quiet or not, with arousal, the presence of choking or the sensation of unrest, the presence of restless movements of the legs are fundamental to precisely define the respiratory disorders, together with snoring. In addition, reports of headache in the morning and excessive daytime sleepiness, which is typically after noon but also may occur in the early morning or whilst driving the car, should be noted.

It is important to record previous or unreported diseases from the patient, life-style and consumption of smoke, alcohol and sleeping pills. A complete, objective physical examination of signs must be performed, including weight (using Lorentz formula or body mass index (weight/height $\left.{ }^{2}\right)$ ) and neck size.

\section{Snoring and cardiovascular apparatus}

Snoring leads to alterations that can reduce the life expectancy of the people afflicted by it. The most dangerous consequences appear to involve the cardiovascular apparatus. The investigations which have been carried out, involving large numbers, often use questionnaires or techniques less complex than polysomnography; for this reason, it is not always easy to discriminate snoring alone from snoring with sleep apnoea. Moreover, haemodynamic monitoring was much less frequently performed than polysomnography in snorers and in snorers with OSA to investigate the direct effect of snoring on the cardiovascular system. In addition, other risk factors for systemic hypertension, such as age, obesity, smoke, diabetes, etc., overlap and cause confusion [8, 53]. WALLER and Bhopal [54] have underlined the discrepancies which may sometimes occur between the various studies.

PARTINEN and PALOMAKI [55] found a three times greater percentage of habitual snorers in 50 consecutive cases of male patients afllicted with cerebral infarct, when compared to a group of neurology in-patients with other pathologies. The studies of LUGARESI and co-workers [7] on the whole population of San Marino, repeated on the inhabitants of a whole quarter of Bologna [7, 56], were first to point out the prevalence of arterial hypertension among heavy snorers, in whom, unlike normal subjects, the systemic arterial pressure does not decrease during the night, but on the contrary slightly increases. The most accepted mechanism by which snoring directly determines cardiovascular effects is that during sleep, snoring develops a more negative intrathoracic pressure, even if the upper airway obstruction is not complete.

On the other hand, by now, most authors consider snoring and "sleep apnoea" as different disorders and, consequently, phases of the same pathology [29, 57, 58]. Nevertheless, other authors deny a correlation between snoring and hypertension [59], and there are also contradictory data concerning the association with the "sleep apnoea" [60, 61].

SMIRNe et al. [62] showed that habitual snoring carries a significant risk factor for stroke and myocardial 
infarction, even after adjusting for other confounding variables, such as age, gender, body mass index, diabetes, dyslipidaemia, smoking, alcohol and hypertension. The association of habitual snoring and acute vascular disease is probably explained by the occurrence of OSA in habitual snorers.

Snoring is, obviously, not only a disturbance for the bed partner and a significant social problem, but also, definitely, a sign of pathology which can range from "of little importance", as in light and initial forms of snoring, to "extremely important" when it is continuous (every night) and heavy. Snoring assumes particular characteristics, besides being a sign of pathology it can also be a trigger or causative factor. There have been no systematic studies on its acoustic features to indicate what kind of snoring can become a trigger or cause of cardiovascular diseases.

\section{Snoring and nasal obstruction}

Partial or total nasal obstruction can variously affect sleep, ventilation and snoring. OLSEN [63] and ZwILLICH [64] demonstrated sleep and breathing disorders in normal subjects with nasal obstruction. LAVIE [65] reported respiratory disorders in the sleep of patients with allergic rhinitis. Bilateral nasal obstruction determines an increase in the number of apnoeas and of their duration in healthy subjects [64]. It has also been demonstrated $[66,67]$ that nasal stimulation or obstruction determines an increase of the lung airways resistance. In normal subjects, nasal obstruction, partial or total, due to various causes (septal deviation, turbinate hypertrophy and other nasal abnormalities) provokes snoring in a high percentage of cases [63-67]. In particular, FAIRBANKS [68], in healthy snorers, found that $80 \%$ of nasal anomalies caused obstruction.

The nasal obstruction itself does not make the nose the site of origin of the snoring and/or of sleep apnoea. It typically determines an increase of the velocity of airflow with the effect of an increased pressure of aspiration and/or an oral breathing; these are factors which can favour pharyngeal collapse and, consequently, snoring up to apnoea. Accurate examination of the nasal cavities is, therefore, mandatory. During direct endoscopic visualization, with instruction of the patient to speak, to simulate snoring, and to carry out the Müller manoeuvre, careful observation of the oral-pharyngeallaryngeal cavity can provide useful information for the expert observer. The analysis of snoring with LPC technique (see "Acoustics of snoring"), starting from acoustic and fluoroscopic studies of simulated snoring, makes it possible to distinguish prevalently nasal, oronasal and oral snoring. The shape of the acoustic airway and the spectral analysis become typical when the nasal obstruction is important or total.

\section{Snoring and asthma}

Another association is that between snoring and asthma, in particular nocturnal asthma. Several complex fac- tors can play a role in its determination, changing the bronchomotor tone, some well-known and demonstrated $[69,70]$, others less known and frequent, such as hypopnoea, and obstructive apnoea with continuous heavy snoring. Nocturnal asthma shows a certain relationship of its attacks with the sleeping stages; MonTPLAISIR et al. [71] noticed a larger incidence of asthma attacks in stage 2 and in REM phase, whilst stages 3 and 4 exerted a certain protection from attacks.

In a recent investigation of snoring and asthma in adults, carried out only on the basis of a complex questionnaire, FITZPATRICK et al. [72] report that asthmatics under $40 \mathrm{yrs}$ of age and "young wheezers" have a higher prevalence of "frequent snoring" than nonasthmatic adults under $40 \mathrm{yrs}$ of age. This fact cannot be referred to a difference in the body mass index between the two groups. The same authors report another well-known association of asthma with excessive daytime sleepiness and the relationship between snoring and daytime somnolence. It has also been pointed out that, in heavy snorer patients affected by nocturnal asthma with or without OSAS, the pharyngeal narrowing associated with heavy snoring, by means of an excessive vagal stimulation, represents the precipitating factor of nocturnal asthma attacks [73]. It is reported that the systematic use of nCPAP in younger patients with nocturnal asthma, without classic OSAS, eliminates nocturnal asthma attacks $[74,75]$.

The mechanisms by which snoring can represent a trigger factor for nocturnal asthma attack can be essentially referred to what follows. Frequent and heavy snoring in asthmatics, due to raised nasal resistance caused by rhinitis or nasal polyposis, could increase the negative pressure on the upper airways thus causing their further narrowing with increased turbulent flow. Snoring and narrowing of the upper airways would indirectly increase the vagal tone because of the continuous repetition of Müller manoeuvres, as indicated by monitoring of the oesophageal pressure [73]. Repeated Müller manoeuvres during sleep would also be involved in the determination of haemodynamic modifications arising during obstructive apnoea or hypopnoea [73].

There have been no studies so far which have determined particular characteristics of snoring in association with snoring-asthma, but the causative mechanisms lead us to suppose that snoring, besides being continuous and heavy, also has the characteristics of typical oral snoring (see "Simulated snoring"). In any case, snoring, apart from representing a trigger factor of attacks, remains a very important, early, and also the most accessible sign to monitor nocturnal asthma. However, there have been no systematic and precise observations on the acoustic features of snoring as a trigger or causative factor of nocturnal asthma.

Snoring as a sign to screen sleep-related breathing disorders $(S R B D)$

Snoring is a central sign, around which various factors and disorders can be found as causes and effects. In particular, loud continuous (every night), intermittent (dur- 
ing the night) snoring is very common in sleep-related breathing disorders with obstruction of the upper airway (i.e. obstructive snoring with arousal and obstructive sleep apnoea). Early diagnosis of SRBD is not easy, but important for therapeutic intervention. For an accurate diagnosis, polysomnography obviously represents a gold standard. This technique is, however, very laborious, time-consuming and expensive; and in Europe, the small number of sleep laboratories cannot admit all suspected patients. The recording of tracheal sounds on the sternal notch allows monitoring of the snoring and breath sounds, and also of sleep apnoea [76, 77]. For these and other reasons, snoring is the constant parameter to be recorded.

Some portable devices were developed and applied for ambulatory and home monitoring of sleep, to screen and/ or select patients for more complex investigations (such as polysomnography). Recently, Penzel and Peter [78] have worked out a concept of stepwise diagnosis of sleep disorders and sleep-related breathing disorders to manage this health risk factor using the Non-Laboratory Monitoring System (NLMS). Evaluation of a questionnaire, clinical investigation and functional tests are accompanied by ambulatory measurements with NLMS (monitoring device: heart rate, snoring, $\mathrm{O}_{2}$-saturation, and body position). If anamnesis and ambulatory recordings with NLMS show that the patient is high risk, longterm recordings for diagnosis and treatment are obtained immediately in the sleep laboratory. If the patient is medium or low risk, further investigation and treatment is performed later in the sleep laboratory or using NLMS. Ambulatory systems are also very useful for long-term observation.

In 1987, Hida et al. [79] developed a device to record and play back, for monitoring sleep at home, nasal flow, tracheal sound and electrocardiogram. In an epidemiological study of 168 workers, they found that the prevalence of patients with SAS in the general population was $17 \%$. This value was unexpectedly higher than the values of a previous paper [56] that surveyed middle-aged men. The present results indicate that there are many undetected patients with sleep apnoea syndrome, and that the portable home sleep monitoring test is helpful in order to find patients with sleep-disordered breathing in a mass survey.

PENZEL and co-workers [80] developed a device, MESAM II, based on snoring and heart rate analysis to monitor sleep apnoea Stoohs and Guilleminault [81] used the same device to screen subjects for OSAS and compare the results with simultaneous polysomnography. The authors [81-85] who have used the MESAM devices (table 3) have compared the discriminant power of the variables digitally analysed, with the objective data of the polysomnography.

The variable snoring, calculated on its energy variation and heart rate have demonstrated a poor correlation with apnoea hypopnoea index (AHI) derived from polysomnography. The sensitivity of these variables is good (96 and 58\%) but the specificity is bad (27 and 39\%). Using MESAM II, StooHs and GuILleminault [81] with "hand scoring" found a specificity of $72 \%$ and a sensitivity of $92 \%$. The variable with the highest performance was $\mathrm{Sa}, \mathrm{O}_{2}$.

Table 3 also shows three other portable devices. DSA model I and II portable systems were further devices for recording tracheal sounds, such as snoring, apnoea, wheezing and cough. These devices have been used by LENS and Postiaux [86, 87] since 1987. With Sleepsound II, a recently developed portable device, the authors found 16 snorers with OSA by sonogram vs five diagnosed clinically, and $4 v s$ three by $\mathrm{Sa}_{\mathrm{a}} \mathrm{O}_{2}$. Another portable device, CID 102, applies the detection of tracheal sounds by two electret sensors and evaluates the sound signal as a function of its frequency range and intensity (dBA). A good correlation was found using this device between the automatic detection of apnoea, and hypopnoea by CID 102 and those evaluated by flow tachograph [43]. Also, Issa et al. [88] developed a new portable digital device (Snoresat), which uses the sound of snoring and $\mathrm{Sa}_{\mathrm{a}} \mathrm{O}_{2}$ to monitor respiratory disturbance (RD). Data were played back and analysed by PC program. Using the RD index, they found a sensitivity and specificity of the device in detecting OSA of between 79-90\% and 90-100\%, respectively, depending on the PGS and RD index value used to define OSA.

The availability of this portable small compact system offers great advantages for the general and specialized physician and patients. These devices fill the big gap in the screening of SRBD. They are, in particular, developed for out-patient use, and enable the physician to make a prompt screening of SRBD, to obtain a diagnosis of SAS, and to screen children or infants with snoring, daytime sleepiness, fatigue and poor school performance, in order to ascertain the upper airway resistance syndrome (UARS) [89-91].

All these five mentioned devices are now based on monitoring of snoring and recording of the snoring signal as present or absent, without additional analysis or measurement. Only when these devices can analyse and measure snoring, will they improve knowledge of it. The systems described make it possible to avoid time-consuming and expensive polysomnography, which can be

Table 3. - An overview of ambulatory, home recording systems available in Europe (digital portable monitoring devices based on snoring sounds)

\begin{tabular}{lccccc}
\hline Parameter & MESAM II & MESAM IV & Sleepsounds II & CID 102 & Snoresat \\
\hline Snoring & $\mathrm{x}$ & $\mathrm{x}$ & $\mathrm{x}$ & $\mathrm{x}$ & $\mathrm{x}$ \\
Heart rate & $\mathrm{x}$ & $\mathrm{x}$ & $\mathrm{x}$ & $\mathrm{x}$ & $\mathrm{x}$ \\
$\mathrm{S}_{\mathrm{a}, \mathrm{O}_{2}}$ & & $\mathrm{x}$ & $\mathrm{x}$ & $\mathrm{x}$ & $\mathrm{x}$ \\
Body position & & $\mathrm{x}$ & & \\
\hline
\end{tabular}

$\mathrm{Sa}_{\mathrm{a}, \mathrm{O}_{2}}$ : arterial oxygen saturation by pulse oximetry. 
reserved for problematic cases. Their versatility, in addition to diagnostic use, can be helpful in monitoring drug and continuous positive airway pressure (CPAP) treatments. Long-term surveillance of patients, who are not at acute risk, can be accomplished at home.

An other important point is the application of snoring monitors to epidemiological studies. We consider that these systems will provide an earlier diagnosis of SRBD and facilitate accurate estimation of prevalence of SAS [79], substantially modifying the epidemiological data so far reported in the literature, as already indicated by HiDA et al. [79].

We would also emphasize that an exclusive study on OSAS, to confirm diagnosis, can only be made with a system such as the polysomnography, to which we must refer for difficult or undetected cases.

\section{Concluding comments}

An important problem in dealing with respiratory sounds, such as snoring, is the comparison of the data of various investigators and correct interpretation. This is due to the fact that each group uses different instruments and devices, and their own recording protocols and data analysis. Thus even if well performed comparison is difficult [92]. In spite of these considerations, some authors are interested in establishing a better definition and quantitation of a phenomenon such as snoring, in more suitable terms such as those of acoustics.

Notwithstanding the recognized differences in the recording phase and analysis of the snoring signal, it is possible to see essential affinities of techniques and results. We refer, in particular, to the general agreement among the works of Righini and Dalmasso [10, 17, 44, 45, 50], Perez-Padilla [39, 46], Spence [47] and Gavriely [40].

A solution to the problem of the need for standardization of instruments and techniques of recording and analysis of respiratory sounds (i.e. lung sounds, cough, snoring and muscles sounds) is one of the present purposes of the International Lungs Sounds Association and of some European investigation groups which are acting in this direction. The data of various authors reported in sections of Acoustics and of Clinical implications and applications even if substantially correct can be improved on the basis of new, more widespread and standardized technologies.

In various pathologies there is sufficient epidemiological data on snoring, but a shortage of relationship data. Moreover, there is a lack of acoustic features of snoring linked to specific disorders. Nowadays, acoustiscs offer some tests for a correct and precise quantitation of snoring. On the other hand, sufficient and comparable studies to attribute to snoring its characteristics as regards the various disorders are lacking. Further studies will better define whether snoring is only a sign and/or a trigger and/or a causative factor of some diseases.

Acoustic tests and parameters, with more extensive use of screening devices for SRBD and/or polysomnography, will be able to distinguish snoring without disturbances from snoring with some sleep-related breathing disturbance and snoring with obstructive sleep apnoea syndrome.

Acknowledgements: The authors thank G. Righini of the Acoustics Department, Istituto Elettrotecnico Nazionale, Galileo Ferraris, Turin for his advice and collaboration, E. Isnardi for his technical assistance and P. Prino for her linguistic assistance.

\section{References}

1. Gastaud H, Tassinari C, Duron B. Etude polygraphique des manifestations épisodiques (hypniques et respiratoire) diurnes et nocturnes du syndrome de Pickwick. Rev Neurol (Paris) 1965; 112: 573-579.

2. Guillemault C, Hill MW, Simmons FB, et al. Obstructive sleep apnoea: electromyographic and fiberoptic studies. Exp Neurol 1978; 62: 48-67.

3. Lugaresi E, Coccagna G, Farneti P, Mantovani M, Cirignotta F. Snoring. Electroencephalogr Clin Neurophysiol 1975; 39: 59-64.

4. Ikematsu T. Study of snoring. IVth report therapy. $J$ Jap Otorhinolaryngol 1964; 64: 334-335.

5. Fujita S, Conway W, Zorick F, et al. Surgical correction of anatomic abnormalities in obstructive sleep apnoea syndrome: uvulopalatopharyngoplasty. Otorlaryngol Head Neck Surg 1981; 89: 923-924.

6. Sullivan C, Berthon-Jones M, Issa F, Eves L. Reversal of obstructive sleep apnoea by continuous positive airways pressure applied through the nares. Lancet 1981; 8225: 862-865.

7. Lugaresi E, Cirignotta F, Coccagna G, Piana C. Some epidemiological data on snoring and cardiocirculatory disturbances. Sleep 1980; 3: 221-224.

8. Shmidt-Nowara WW, Coultas DB, Wigins C, Skipper BE, Samet JM. Snoring in a Hispanic-American population: risk factor and association with hypertension and other morbidity. Arch Intern Med 1990; 150: 597601.

9. Dalmasso F, Benedetto G, Righini G, Spagnolo R. Snoring sound analysis and acoustic tube model of upper airway. Proceedings of the 14th International Conference on Lung Sounds, Winnipeg, 1989.

10. Dalmasso F, Garati P, Ono M, Prota R, Righini G. Snoring on-line monitoring system. Proceedings of the 15th International Conference on Lung Sounds, New Orleans, 1990.

11. Lugaresi E, Mondini S, Zucconi M, Montagna P, Cirignotta F. Staging of heavy snorers' disease: a proposal. Bull Eur Physiopathol Respir 1983; 19: 590-594.

12. Thorpy MJ (chairman). The international classification of sleep disorders: diagnostic and coding manual. Lawrence KS, ed. Allen Press Inc., USA 1990; pp. 195-197.

13. Hoffstein V, Mateika JH, Mateika S. Snoring and sleep architecture. Am Rev Respir Dis 1991; 143: 92-96.

14. Bellia V, Cuttitta G, Insalaco G, Visconti A, Bonsignore G. Relationship of nocturnal bronchoconstriction to sleep stages. Am Rev Respir Dis 1989; 140: 363-367.

15. Guilleminault C, Quera-Salva MA, Powell N, et al. Nocturnal asthma: snoring, small pharynx, and nasal CPAP. Eur Respir J 1988; 1: 902-907.

16. Chan CS, Woolcock AJ, Sullivan CE. Nocturnal asthma: role of snoring and obstructive sleep apnoea. Am Rev Respir Dis 1988; 137: 1502-1504.

17. Dalmasso F, Benedetto G, Righini G, Spagnolo R. Digital processing of snoring sounds. Eur Respir J 1990; 3 (Suppl. 11): 528-532.

18. Kane JW, Sternhe MM. Life Science Physics. 2nd Edn, New York, John Wiley \& Sons Inc., 1979; Vol I.

19. Hyatt RE, Wilcox RE. Extrathoracic airway resistance 
in man. J Appl Physiol 1961; 16: 326-330.

20. Spann RW, Hyatt RE. Factors affecting upper airway resistance in conscious man. J Appl Physiol 1971; 31: 708-712.

21. Ferris BG, Mead J, Opie LH. Partitioning of respiratory flow resistances in man. J Appl Physiol 1964; 19: 653-658.

22. Strohl KP, Hensley MJ, Saunders NA, Ingram RH. Activation of upper airway muscles before the onset of inspiration in normal humans. J Appl Physiol: Respirat Environ Exercise Physiol 1980; 49: 638-642.

23. Sauerland FC, Orr WC, Hairston LE. EMG patterns of oropharyngeal muscles during respiration in wakefulness and sleep. Electormyogr Clin Neurophysiol 1981; 21: 307-316.

24. Hudgel DW, Martin RJ, Johnson B, Hill P. Mechanics of the respiratory system and breathing pattern during sleep in normal humans. J Appl Physiol: Respirat Environ Excercise Physiol 1984; 56: 133-137.

25. Wiegland L, Zwillich CW, White DP. Collapsibility of the human upper airway during normal sleep. J Appl Physiol 1989; 66: 1800-1808.

26. Sauerland EK, Harper RM. The human tongue during sleep: electromyographic activity of the genioglossus muscle. Exp Neurol 1976; 51: 160-170.

27. Wiegand DA, Zwillich CW, Latz B, Wiegand L. The influence of sleep on geniohyoid muscle activity and supraglottic airway resistance. Am Rev Respir Dis 1989; 139: A447.

28. Tangel PJ, Mezzanotte WS, White D. Influence of sleep on tensor palatini EMG and upper airway resistance in normal men. J Appl Physiol 1991; 70: 2574-2581.

29. Hoffstein V, Chaban R, Cole P, Rubinstein I. Snoring and upper airway properties. Chest 1988; 94: 87-89.

30. Hudgel DW, Hendricks C. Palate and hypopharynx sites of inspiratory narrowing of the upper airway during sleep. Am Rev Respir Dis 1988; 138: 1542-1547.

31. Skatrud JB, Dempsey JA. Airway resistance and respiratory muscle function in snorers during NREM sleep. J Appl Physiol 1985; 59: 328-335.

32. Remmers JE, Feroah T, Perez-Pedilla JR, Whitelaw WA. Correlation of structure and mechanics in pharyngeal obstruction during sleep. In: Chouard $\mathrm{CH}$, ed. Chronic Rhonchopathy. Paris, John Libbey, 1987; pp. 30-35.

33. Liistro G, Stanescu DC, Veriter C, Rodenstein DO, AubertTulkens G. Pattern of snoring in obstructive sleep apnea patients and in heavy snorers. Sleep 1991; 14(6): 517-525.

34. Perez-Padilla JR, West P, Kryger M. Snoring in normal young adults: prevalence in sleep stages and associated changes in oxygen saturation, heart rate, and breathing pattern. Sleep 1987; 10: 249-253.

35. Conrad WA. Pressure-flow relationships in collapsible tubes. IEEE Trans Biomed Eng 1969; 16: 284-295.

36. Grotberg JB, Davies SH. Fluid-dynamic flapping of a collapsible channel: sound generation and flow limitation. J Biomech 1980; 13: 219-230.

37. Grotberg JB, Gavriely N. Flutter in collapsible tubes: a theoretical model of wheezes. J Appl Physiol 1989; 66: 2262-2273.

38. Bertram CD. Two models of instability in a thick-walled collapsible tube conveying a flow. J Biomech 1982; 15 : 223-224.

39. Perez-Padilla R, Remmers JE. Dynamics of pressure, airflow and noise production during simulated snoring. Am Rev Respir Dis 1985; 131: 106 (Abstract).

40. Gavriely N, Shee TR, Cugell DW, Grotberg JB. Flutter in flow-limited collapsible tubes: a mechanism for gen- eration of wheezes. J Appl Physiol 1989; 66: 2251-2261.

41. Hassal JR, Zaveri K. Acoustic noise measurements. Naerum, Denmark, Bruel \& Kjaer, 1979; pp. 53-58.

42. Wilson K, Mulrooney T, Gawtry RR. Snoring: an acoustic monitoring technique. Laryngoscope 1985; 95: 1174-1177.

43. Meslier N, Person C, Badatcheff A, Racineux JL. Automatic tracheal breath sound analysis for identification of apneic and non-apneic snorers. Am Rev Respir Dis 1992; 145: A174.

44. Dalmasso F, Prota R, de Vicaris A, Fava C, Righini P, Righini G. Acoustic and fluoroscopic data relationship in the measurement of cross- sectional area (CSA) in simulated snoring. Eur Respir J 1993; 6 (Suppl. 17): 457S.

45. Dalmasso F, Righini G, Sirkka M, Prota R, Righini P, Valmaggia P. Analysis of simulated snoring by linear prediction (LPC) method. Eur Respir J 1991; 4 (Suppl. 14): $381 \mathrm{~s}$

46. Perez-Padilla JR, Slawinski E, Difrancesco LM, Feige RR, Remmers JE, Whitelaw WA. Characteristics of the snoring noise in patients with and without sleep apnea. Am Rev Respir Dis 1993; 147: 635-644.

47. Spence DSP, Ishaque N, Jamieson G, Calverly PMA, Earis JE. The relationship between snore frequency and severity of obstructive sleep apnoea (OSA). Proceedings of the 18th International Conference on Lung Sounds. Lake Louis, Alberta, Canada, 1993.

48. Cohen A, Leiberman A. Characterization and recognition of snoring and stridor signal. Proceedings of the 15th IEE Cong. Elect. Eng., Tel-Aviv, 1987; pp. 1-4.

49. Fant G. Analysis and synthesis of speech processes. In: Malmberg B, ed. Manual of Phonetics. Amsterdam, North-Holland Publishing Co., 1968; pp. 173-277.

50. Dalmasso F, Righini G, Fava C, Prota R, de Leonardis F, Righini P. Snoring: measurement and analysis. Monaldi Arch Chest Dis 1993; 48(5): 589-595.

51. Liistro G, Stanescu D, Veriter C. Pattern of simulated snoring is different through mouth and nose. J Appl Physiol 1991; 70(6): 2736-2741.

52. Perrier P, Boè LJ, Sock R. Vocal tract area function estimation from midsagittal dimensions with CT scans and a vocal tract cast: modelling the transition with two sets of coefficients. J Speech Hearing Res 1992; 35: 53-67.

53. Bloom JW, Kaltenborn WT, Quan SF. Risk factors in a general population for snoring: importance of cigarette smoking and obesity. Chest 1988; 93: 678-683.

54. Waller PC, Bhopal RS. Is snoring a cause of vascular disease? An epidemiological review. Lancet 1989; i: 143-146.

55. Partinen M, Palomaki H. Snoring and cerebral infarction. Lancet 1985; ii: 1325-1326.

56. Cirignotta F, D'Alessandro R, Partinen M, et al. Prevalence of every night snoring and obstructive sleep apnoeas among 30-69 year old men in Bologna, Italy. Acta Neurol Scand 1989; 79: 366-372.

57. Mendelson WB. Human sleep: research and clinical care. New York, Plenum Publishing Corp., 1987.

58. Bradley TD, Brown IG, Grossman RF, et al. Pharyngeal size in snorers, nonsnorers, and patients with obstructive sleep apnea. N Engl J Med 1986; 315: 1327-1331.

59. Stradling JR, Crosby JH. Relation between systemic hypertension and sleep hypoxaemia or snoring: analysis in 748 men drawn from general practice. $\mathrm{Br}$ Med J 1990; 300: 75-78.

60. Williams AJ, Houston D, Finberg S, Lam C, Kinney L, Santiago S. Sleep apnea syndrome and essential hyper- 
tension. Am J Cardiol 1985; 55: 1019-1022.

61. Escourrou P, Jirani A, Nedelcoux H, Duroux P, Gaultier C. Systemic hypertension in sleep apnea syndrome: relationship with sleep architecture and breathing abnormalities. Chest 1990; 98: 1362-1365.

62. Smirne S, Palazzi S, Zucconi M, Chierchia S, FeriniStrambi L. Habitual snoring as a risk factor for acute vascular disease. Eur Respir J 1993; 6: 1357-1361.

63. Olsen KD. Sleep and breathing disturbance secondary to nasal obstruction. Arch Otolaryngol Head Neck Surg 1981; 89: 804-810.

64. Zwillich CW. Disturbed sleep and prolongeal apnea during nasal obstruction in normal man. Am Rev Respir Dis 1981; S124: 158-160.

65. Lavie P. Breathing disorders in sleep associated with "micro-arousal" in patients with allergic rhinitis. Acta Otolaryngol 1981; 92: 529-533.

66. Widdicombe JG. Upper airway resistance and snoring in anesthesized dogs. Eur Respir J 1988; 1(9): 779-784.

67. Ogura JH. Nasopulmonary mechanics: experimental evidence of the influence of the upper airway upon the lower. Acta Otolaryngol 1971; 71: 123.

68. Fairbanks MD. Snoring surgical versus nonsurgical management. Laryngoscope 1988; 94: 1188-1192.

69. Cropp GJA. The role of the parasympathetic nervous systems in the maintenance of chronic airway obstruction in asthmatic children. Am Rev Respir Dis 1975; 112: 599-605.

70. Coe CI, Barnes PJ. Reduction of nocturnal asthma by an inhaled anticholinergic drug. Chest 1986; 90: 485488.

71. Montplaisir J, Walsh J, Malo J. Nocturnal asthma: features of attacks, sleep and breathing patterns. Am Rev Respir Dis 1982; 125: 18-22.

72. Fitzpatrick MF, Martin K, Fossey E, Shapiro CM, Elton RA, Douglas NJ. snoring, asthma and sleep disturbance in Britain: a community-based survey. Eur Respir $J$ 1993; 6: 531-535.

73. Guilleminault C, Quera-Salva MA, Powell N, et al. Nocturnal asthma: snoring, small pharynx and nsal CPAP. Eur Respir J 1988; 1: 902-907.

74. Chan CS, Yan K, Woolcock AJ, Sullivan CE. The effect of nasal CPAP on patients with asthma and obstructive sleep apnea. Am Rev Respir Dis 1986; 133: 343 (Abstract).

75. Guilleminault C, Quera-Salva MA, Powell N, et al. Nocturnal asthma, upper airway anatomical abnormalitiy and nasal CPAP. Sleep Res 1987; 16: 477 (Abstract).

76. Krumpe PE, Cummiskey JM. Use of laryngeal sound recordings to monitor apnea. Am Rev Respir Dis 1980; 122: 797-801.

77. Cummiskey J, Williams TC, Krumpe PE, Guilleminault C. The detection and quantification of sleep apnea by tracheal sound recordings. Am Rev Respir Dis 1982;
126: 221-224.

78. Penzel T, Peter JH. Ambulatory diagnosis of sleep-related breathing disorders. Sleep 1992; 15: S9-S12.

79. Hida W, Shindoh C, Okabe S, et al. Prevalence of sleep apnea syndrome in Japanese industrial workers using a home sleep monitor. Sleep 1993; 16: S126-S127.

80. Penzel T, Peter JH, Von Vichert P. Spectral analysis of heart rate and blood pressure in sleep apnea syndrome. In: Gaultier C, Escourrou P, Curzi-Dascalova L, eds. Sleep and Cardiorespiratory Control. London/Paris, College INSERM John Libbey Eurotext, Vol. 217, 1992; pp. 79-85.

81. Stoohs R, Guilleminault C. Investigations of an automatic screening device (MESAM) for obstructive sleep apnoea. Eur Respir J 1990; 3: 823-829.

82. Penzel T, Amend G, Meinzer K, Peter JH, Von Wichert P. MESAM: a heart rate and snoring recorder for detection of obstructive sleep apnea. Sleep 1990; 13: 175182.

83. Stoohs RA, Guilleminault C. MESAM 4: an ambulatory device for the detection of patients at risk for obstructive sleep apnea syndrome (SAS). Chest 1992; 101: 1221-1227.

84. Rauscher H, Popp W, Zwick H. Quantification of sleepdisordered breathing by computerized analysis of oximetry, heart rate and snoring. Eur Respir J 1991; 4: 655-659.

85. Stoohs RA, Guilleminault C, Dement WC. Sleep apnea and hypertension in commercial truck drivers. Sleep 1993; 16: S11-S14.

86. Lens E, Postiaux G. Automated sounds analysis of respiratory cycle: sonospirogram. Proceedings of the 12th International Conference on Lung Sounds, Paris, 1987.

87. Lens E, Postiaux G. Feasibility of simultaneous recording and analysis of nocturnal breath sounds (wheezing, snoring, apnea), oesophageal pHmetry, ear oximetry. Proceedings of the 13th International Conference on Lung Sounds, Chicago, 1988.

88. Issa FG, Morrison D, Hadjuk E, et al. Digital monitoring of obstructive sleep apnea using snoring sound and arterial oxygen saturation. Sleep 1993; 16: S132.

89. Guilleminault C, Winkle R, Korobkin R, Simmons B. Children and nocturnal snoring-evaluation of the effects of sleep-related respiratory resistive load and daytime functioning. Eur J Pediatr 1982; 139: 165-171.

90. Downey R III, Perkin RM, MacQuarrie J. Upper airway resistance syndrome: sick, symptomatic but underrecognized. Sleep 1993; 16(7): 620-623.

91. Guilleminault C, Stoohs RA, Clerk A, Simmons J, Labanowski M. From obstructive sleep apnoea syndrome to upper airway resistance syndrome: consistency of daytime sleepiness. Sleep 1992; 15: S13-S16.

92. Mussel MJ. The need for standards in recording and analysing respiratory sounds. Med Biol Eng Comput 1992; 30: 129-139. 